\title{
Pdc2/Pat1 increases the range of decay factors and RNA bound by the Lsm1-7 complex
}

\author{
JOSEPH H. LOBEL ${ }^{1,2}$ and JOHN D. GROSS ${ }^{2}$ \\ ${ }^{1}$ Chemistry and Chemical Biology Graduate Program, University of California, San Francisco, San Francisco, California 94158, USA \\ ${ }^{2}$ Department of Pharmaceutical Chemistry, University of California, San Francisco, San Francisco, California 94158, USA
}

\begin{abstract}
Pat1, known as Pdc2 in fission yeast, promotes the activation and assembly of multiple proteins during mRNA decay. After deadenylation, the Pat1/Lsm1-7 complex binds to transcripts containing oligo(A) tails, which can be modified by the addition of several terminal uridine residues. Pat1 enhances Lsm1-7 binding to the $3^{\prime}$ end, but it is unknown how this interaction is influenced by nucleotide composition. Here we examine Pat1/Lsm1-7 binding to a series of oligoribonucleotides containing different $\mathrm{A} / \mathrm{U}$ contents using recombinant purified proteins from fission yeast. We observe a positive correlation between fractional uridine content and Lsm1-7 binding affinity. Addition of Pat1 broadens RNA specificity of Lsm1-7 by enhancing binding to A-rich RNAs and increases cooperativity on all oligonucleotides tested. Consistent with increased cooperativity, Pat1 promotes multimerization of the Lsm1-7 complex, which is potentiated by RNA binding. Furthermore, the inherent ability of Pat 1 to multimerize drives liquid-liquid phase separation with multivalent decapping enzyme complexes of Dcp1/Dcp2. Our results uncover how Pat1 regulates RNA binding and higher order assembly by mRNA decay factors.
\end{abstract}

Keywords: mRNA decay; Pat1; Lsm1; P-bodies; Dcp2; Pdc2

\section{INTRODUCTION}

A dense network of protein-protein interactions regulates 5'-3' mRNA decay, which is important for gene expression and many physiological processes including development, microRNA-mediated decay, and quality control mechanisms (Moore 2005; Jonas and Izaurralde 2015; Mugridge et al. 2018; Kurosaki et al. 2019). Bulk 5'-3' mRNA degradation begins with the trimming of the $3^{\prime}$ poly(A) tail by cytoplasmic deadenylases, which can be followed by addition of several uridines by terminal uridine transferases in fission yeast and metazoans (Rissland and Norbury 2009; Lim et al. 2014; Mugridge et al. 2018; Webster et al. 2018; Yi et al. 2018). After deadenylation and subsequent uridylation, the heterooctameric Pat1/ Lsm1-7 complex assembles on or near the 3' A/U-rich deadenylated tail of the mRNA (Bonnerot et al. 2000; Bouveret et al. 2000; Tharun et al. 2000; Tharun and Parker 2001; Mitchell et al. 2012; Wang et al. 2017). Pat1 activates proteins at both the $5^{\prime}$ and $3^{\prime}$ end of the mRNA by enhancing RNA binding of the Lsm1-7 complex to the deadenylated $3^{\prime}$ end and decapping by the Dcp1/ Dcp2 complex (Nissan et al. 2010; Chowdhury et al.

Corresponding author: jdgross@cgl.ucsf.edu

Article is online at http://www.rnajournal.org/cgi/doi/10.1261/rna. 075812.120. Freely available online through the RNA Open Access option.
2013; Charenton et al. 2017; Lobel et al. 2019). Deletion of Pat1 results in accumulation of poorly translated, deadenylated, capped transcripts, suggesting a block in decapping (Tharun and Parker 2001; Wang et al. 2017; He et al. 2018).

Many mRNA decay factors, including Pat1, are enriched in processing-bodies (P-bodies), which are a class of membraneless organelles that may function in mRNA storage or decay (Sheth and Parker 2003; Teixeira and Parker 2007; Hubstenberger et al. 2017; Xing et al. 2018). At the molecular level, these structures are promoted by multivalent protein-protein and protein-nucleic acid interactions that are required for liquid-liquid phase separation (Banani et al. 2017). Overexpression of Pat1 enhances Pbody formation in fungi, suggesting its importance in assembling these structures (Wang et al. 2017; Sachdev et al. 2019). Therefore, Pat1 functions at multiple steps during $5^{\prime}-3^{\prime}$ mRNA decay to coordinate degradation of the transcript.

Pat1 uses a combination of disordered and globular domains to interact with and activate multiple mRNA decay factors. The disordered amino terminus contains a conserved FDF motif that interacts with Dhh1 (DDX6 in humans) and potentiates P-body formation, but is largely

(C) 2020 Lobel and Gross This article, published in RNA, is available under a Creative Commons License (Attribution 4.0 International), as described at http://creativecommons.org/licenses/by/4.0/. 
dispensable for function (Pilkington and Parker 2008; Sharif et al. 2013; Sachdev et al. 2019). The unstructured middle domain contains multiple short linear interaction motifs (SLiMs) and cooperates with the structured carboxy-terminal domain to activate RNA binding by Lsm1-7 and decapping by the Dcp1/Dcp2 complex through multiple mechanisms (Pilkington and Parker 2008; Chowdhury et al. 2013; Lobel et al. 2019).

While it is known how Pat1 activates different mRNA decay factors, much less is understood about how it affects specific RNA recognition by Lsm1-7. In vitro, budding yeast Pat1/Lsm1-7 shows a preference for oligoadenylated RNAs compared to those containing poly(A) tails; however, genome-wide CLIP studies indicate Pat1/Lsm1 co-occupy the $3^{\prime}$ untranslated region (UTR) of budding yeast transcripts without enriching a specific sequence motif (Chowdhury et al. 2007; Mitchell et al. 2012). In fission yeast and metazoan cells, deletion of Lsm1 or Pat1 stabilizes mRNA decay intermediates with oligo(A) tails containing several uridines (Rissland and Norbury 2009; Lim et al. 2014). Furthermore, in mammalian cells, knockdown of Pat1 stabilizes transcripts with AU-rich sequences in the 3'-UTR (Vindry et al. 2017). Lsm1-7 can also bind oligo(U) RNA sequences in vitro and promotes decay of histone mRNAs that contain U-rich tails in cells (Chowdhury et al. 2007; Mullen and Marzluff 2008; Wu et al. 2014). How Pat1 affects location and sequence specificity of the Lsm1-7 complex on mRNA is poorly understood.

In this work, we evaluate recombinant purified Schizosaccharomyces pombe Pat1/Lsm1-7 complex binding to a series of oligonucleotides of different $A / U$ content. Lsm1-7 alone has a binding preference for U-rich RNAs. Addition of Pat1, however, broadens the specificity of the Lsm1-7 complex by enhancing binding to A-rich targets. Furthermore, Pat1 increases cooperative binding of Lsm1-7 to oligonucleotides, which drives multimerization of the heterooctamer on RNA in a sequence independent manner. Oligomerization is an inherent property of Pat1 that permits higher order assembly with multivalent Dcp1/Dcp2 complexes, which can recruit additional mRNA decay machinery. Taken together, this work reveals how Pat1 broadens the specificity of Lsm1-7 and promotes the assembly of higher order decapping complexes.

\section{RESULTS}

\section{The PatMC/Lsm1-7 complex cooperatively binds to A-rich RNA}

Previous studies indicate that the middle and carboxy-terminal domains of Pat1 (termed PatMC) are sufficient to support cell growth in yeast (Pilkington and Parker 2008; Lobel et al. 2019). To understand how different $3^{\prime}$ end sequences influence PatMC/Lsm1-7 binding, we tested recombinant purified S.pombe Lsm1-7 complexes alone or coexpressed with PatMC for their ability to bind different oligo-RNAs by fluorescence polarization (Fig. 1A,B). Because global profiling of RNA tails indicate that uridine residues are found on short tails ( $<25 \mathrm{nt})$, we investigated a series of 15 mers containing different adenine and uracil contents (Rissland and Norbury 2009; Chang et al. 2014). As seen previously, PatMC enhanced the RNA binding of Lsm1-7 to A15 RNA 20-fold (Lobel et al. 2019). The foldenhancement of Lsm1-7 RNA binding by PatMC strongly correlated with the fractional adenine content of the $15 \mathrm{mer}$, where a greater difference in free energy of binding was observed for more adenine-rich substrates (Fig. 1C; Supplemental Fig. S1A-F; Supplemental Table S1). Furthermore, the Lsm1-7 complex alone strongly favored binding to U-rich 15 mers, which was not affected by PatMC. In the absence of PatMC, Lsm1-7 preferentially bound A-tailed RNAs with similar uracil content, suggesting that nucleotide context may be an additional factor for Lsm1-7 binding RNA (Fig. 1C). Because PatMC binds RNA weakly on its own, PatMC may serve to selectively enhance RNA binding of Lsm 1-7 to adenine rich tails and may be dispensable for engaging U-rich tails (Supplemental Fig. S1G; Lobel et al. 2019).

In addition to the differences in affinities for the oligonucleotides, we also observed a difference in Hill coefficients, a measure of cooperativity that places a lower bound on the number of Pat1/Lsm1-7 complexes binding RNA. The binding isotherms of the PatMC/Lsm1-7 complex were consistently approximately twofold more cooperative than Lsm1-7 alone for all tested RNAs, suggesting that PatMC/Lsm1-7 may be engaging A15 and U15 RNA in a different manner (Fig. 1D). Specifically, PatMC/ Lsm1-7 had a Hill coefficient of $\sim 1$ for U15 RNA and 2 for A15 RNA, suggesting that binding to A15 is cooperative while U15 binding is not. This indicates that at least one or two copies of the PatMC/Lsm1-7 complex cooperatively bind to U15 or A15 RNA, respectively.

\section{Short RNAs are sufficient to promote dimerization of the PatMC/Lsm1-7 complex}

To directly test the number of PatMC/Lsm1-7 complexes bound to short oligonucleotides, we used size exclusion chromatography coupled to multiangle light scattering (SEC-MALS). The SEC step fractionates protein complexes by hydrodynamic radius and molar mass is concurrently detected by light-scattering and differential refractometry (Wyatt 1993). The PatMC/Lsm1-7 complex was incubated with stoichiometric amounts of A15 RNA and subjected to SEC-MALS. The A15 RNA promoted the formation of two peaks that had identical protein composition and molar masses corresponding to that of a dimeric (two copies of PatMC/Lsm1-7) and tetrameric assembly (Table 1; Fig. 2A). Shorter RNAs, such as A10, also promoted oligomeric 
A

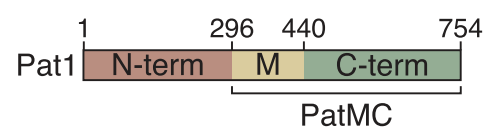

C

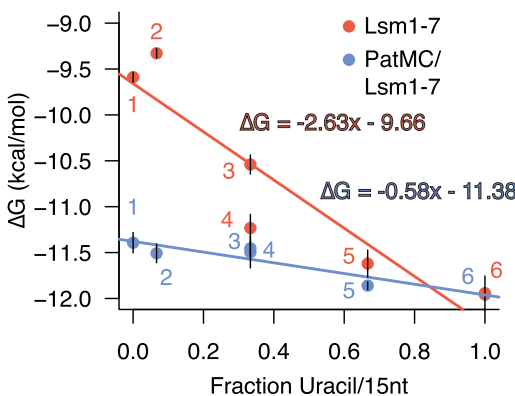

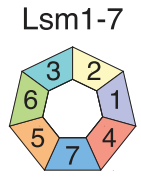

D

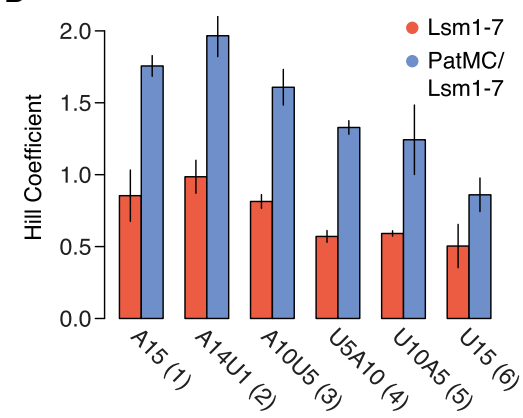

FIGURE 1. PatMC enhances Lsm1-7 binding to adenine-rich substrates in a cooperative manner. (A) Schematic of Pat1 domains and Lsm1-7. (B) SDS-PAGE of the Lsm1-7 complex alone (left) or with PatMC (right). Molecular weight $(\mathrm{kDa})$ shown on right. $(C)$ Lsm1-7 or PatMC/ Lsm1-7 binding to different 5'-FAM labeled 15mer RNAs (A15, A14U1, A10U5, U5A10, U10A5, U15) monitored by fluorescence polarization. Numbers correspond to labels in (D). Binding affinities were converted to $\Delta \mathrm{G}$ and plotted against the fractional uracil content of the oligonucleotides $(n=3)$. (D) Hill coefficients for each fit for the binding isotherms shown in $C(n=3)$.

PatMC/Lsm1-7 assemblies, with molar masses corresponding to dimeric and tetrameric complexes (Fig. 2B). However, we observed that the A10 RNA reduced tetramerization and instead produced predominantly dimeric PatMC/Lsm1-7 complexes, based on the relative ratio of the peaks in the chromatogram. This suggests that RNA length may influence tetramerization, but short RNAs still promote higher order assembly of the PatMC/Lsm1-7 complex.

To evaluate the stability of the oligomeric assemblies, we performed sedimentation velocity analytical ultracentrifugation (SV-AUC) on PatMC/Lsm1-7 with stoichiometric amounts of A15 RNA over the course of $12 \mathrm{~h}$. While we could detect a strong dimeric peak in the sedimentation distribution, there was a minimal amount of tetrameric assemblies (Fig. 2C). Furthermore, the tetrameric fraction

of the PatMC/Lsm1-7/A15 complex disassembled into dimers and tetramers upon reinjection over a size exclusion column, while the dimeric peak did not further dissociate (Supplemental Fig. S2A-C). This suggests that the tetrameric PatMC/ Lsm1-7/RNA complex is less stable than the dimeric species.

We next asked how PatMC/Lsm1-7 assembled on U15 RNA. As seen with A15 RNA, addition of stoichiometric amounts of U15 to the PatMC/ Lsm1-7 complex resulted in two peaks by SEC-MALS with molar masses corresponding to dimeric and tetrameric assemblies (Fig. 3A,B). This effect depends on PatMC, because Lsm1-7 alone bound to U15 RNA remained monomeric (Fig. 3C). Taken together, this indicates that PatMC promotes the higher order assembly of the PatMC/Lsm1-7 complex on both $A 15$ and U15 RNA. This suggests that while both $\mathrm{A} 15$ and $\mathrm{U} 15$ promote dimerization of the PatMC/Lsm1-7 complex, some of the contacts of the dimer may differ, as evidenced by the difference in RNA binding cooperativity (Fig. 1D).

It is possible that each PatMC/Lsm1-7 complex binds an individual RNA or that multiple PatMC/Lsm1-7 complexes co-occupy a single RNA to promote oligomerization. To test these possibilities, we determined the stoichiometry of PatMC/Lsm1-7 binding to RNA. Experiments were performed under saturating conditions, where concentration of the oligo-RNA was far above the $K_{d}$. Binding of labeled U15 was followed by fluorescence anisotropy. Titration of Lsm1-7 alone or the PatMC/Lsm1-7 complex results in saturation of the anisotropy signal at one equivalent of RNA, indicating 1:1 binding between PatMC/Lsm1-7 and the U15 oligonucleotide (Fig. 3D). Similar results were obtained for PatMC/Lsm1-7 binding to A15 (Supplemental

TABLE 1. Molecular weight determination by SEC-MALS

\begin{tabular}{lccc}
\hline $\begin{array}{l}\text { Protein + RNA } \\
\text { complex }\end{array}$ & $\begin{array}{c}\text { Expected monomer molar } \\
\text { mass }(\mathrm{kDa})\end{array}$ & $\begin{array}{c}\text { Observed molar mass, } \\
\text { peak 1 (kDa) }\end{array}$ & $\begin{array}{c}\text { Observed molar mass, } \\
\text { peak 2 }(\mathrm{kDa})\end{array}$ \\
\hline PatMC/Lsm1-7 & 133.5 & $304.5( \pm 1.20 \%)$ & $160.3( \pm 0.93 \%)$ \\
PatMC/Lsm1-7+A15 & 138.2 & $576.0( \pm 1.28 \%)$ & $273.3( \pm 0.56 \%)$ \\
PatMC/Lsm1-7+A10 & 136.6 & $554.2( \pm 0.80 \%)$ & $275.5( \pm 0.26 \%)$ \\
PatMC/Lsm1-7+ U15 & 137.8 & $548.1( \pm 0.91 \%)$ & $268.1( \pm 0.88 \%)$ \\
Lsm1-7 + U15 & 85.6 & $243.9( \pm 6.3 \%)$ & $86.1( \pm 2.40 \%)$ \\
\hline
\end{tabular}

Expected and observed molar masses of SEC-MALS chromatograms. Error is displayed in parentheses to the right of observed peak. Peak 1 and 2 refers to the earlier and later elution volume peaks, respectively. 
A PatMC/Lsm1-7+A15

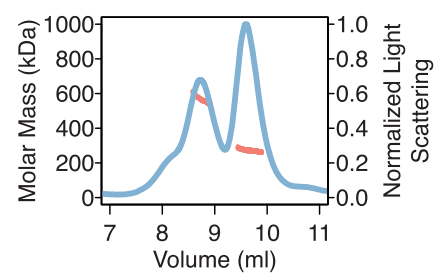

B PatMC/Lsm1-7+A10

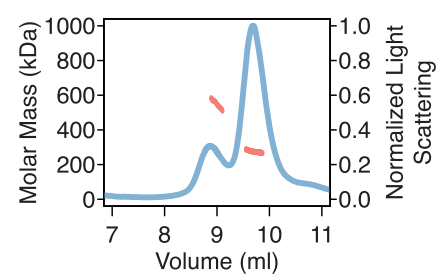

C

PatMC/Lsm1-7+A15

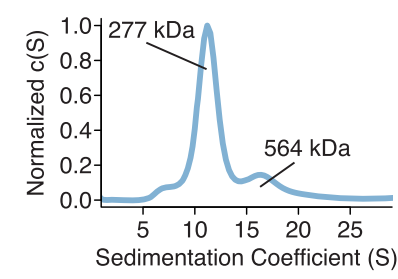

FIGURE 2. RNA promotes stable dimerization of the PatMC/Lsm1-7 complex. $(A, B)$ SEC-MALS of $20.6 \mu \mathrm{M}$ PatMC/Lsm1-7 with stoichiometric (A), A15 and (B), A10 RNA. Expected and observed molar masses are shown in Table 1. The light scattering (blue) and molar mass (red) are displayed. (C) SV-AUC of $9.3 \mu \mathrm{M}$ PatMC/Lsm1-7 with stoichiometric $\mathrm{A} 15 \mathrm{RNA}$ at $250 \mathrm{mM} \mathrm{NaCl}$. c(S) is the sedimentation distribution with molecular weights determined from fits.

Fig. S3). This indicates that each PatMC/Lsm1-7 heterooctamer binds a single oligo-RNA, though we cannot exclude the possibility that PatMC/Lsm1-7 can co-occupy RNA sequences longer than 15 nt tested here. Therefore, we conclude that RNA ligands of different sequences and lengths induce stable dimerization of the PatMC/Lsm1-7 complex.

\section{Dimerization is an intrinsic property of the PatMC/Lsm1-7 complex}

As PatMC/Lsm1-7 binds to RNA as a higher order assembly, we asked if the complex had the intrinsic ability to multimerize in the absence of RNA. While PatMC/Lsm1-7 initially purified as a monomer, concentration and subsequent SEC-MALS of the complex in the absence of RNA revealed two peaks with molar masses corresponding to monomeric and dimeric PatMC/Lsm1-7 complexes (Fig. 4A-C). This indicates that the PatMC/Lsm1-7 complex has the inherent ability to form multimers independent of nucleic acid.

To test the stability of the assemblies in the absence of RNA, we performed SV-AUC on the PatMC/Lsm1-7 com- plex alone. Over the course of $12 \mathrm{~h}$, we observed both a monomeric and dimeric species, indicating that both these complexes were stable (Fig. 4D). Furthermore, increasing salt concentrations favored monomerization of the complex, indicating PatMC/Lsm1-7 oligomerization is reversible (Supplemental Fig. S4). Because Lsm1-7 was monomeric in the absence of PatMC, the above results indicate PatMC drives multimerization of Lsm1-7, which may be enhanced by RNA binding (Figs. 2A, 3A).

\section{PatMC promotes liquid-droplet formation with Dcp2 and recruits additional mRNA decay factors}

Previous studies demonstrate that the monomeric, globular carboxy-terminal domain of Pat1 can bind helical leucine motifs (HLMs) in the disordered carboxyl terminus of Dcp2 (Charenton et al. 2017; Lobel et al. 2019). Known dimeric HLM binding proteins, such as Edc3, can interact with Dcp2 and undergo liquid-liquid phase separation with Dcp2 constructs that contain multiple HLMs (Fromm et al. 2014; Schutz et al. 2017). Our biochemical data demonstrate that PatMC can inherently oligomerize in the absence of RNA, so we tested if it could promote liquidliquid phase separation with multivalent Dcp1/Dcp2 complexes, analogous to Edc3. PatMC was purified fused to maltose-binding protein (MBP) to enhance its solubility (see Materials and Methods). It was then mixed with a Dcp2 construct containing both the catalytic core and three HLMs in the disordered carboxyl terminus extension, along
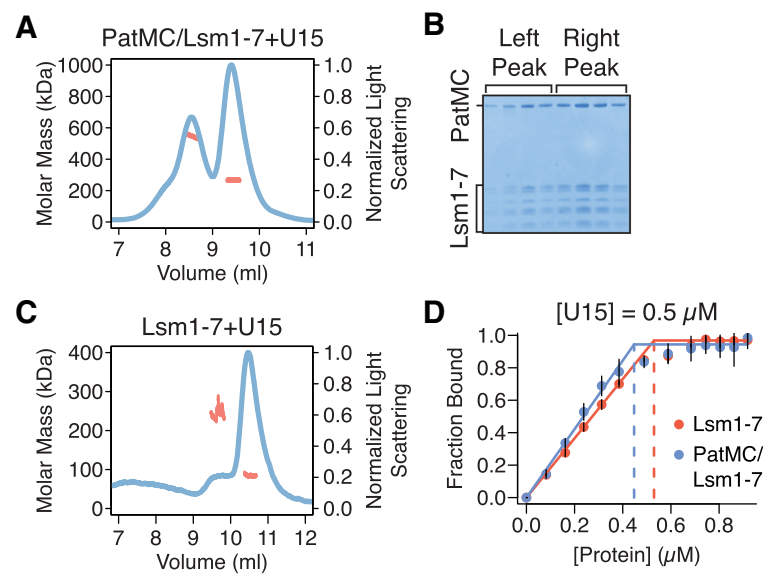

FIGURE 3. Multiple RNA sequences drive higher order PatMC/ Lsm1-7 assembly in a Pat1-dependent manner. (A) SEC-MALS of 20.6 $\mu \mathrm{M}$ PatMC/Lsm1-7 with stoichiometric U15 RNA. The expected molar mass of the monomeric PatMC/Lsm1-7 complex is $133 \mathrm{kDa}$. (B) Representative SDS-PAGE gel of fractions in A. (C) SEC-MALS of 20.6 $\mu \mathrm{M}$ Lsm1-7 with stoichiometric U15 RNA. The expected mass of the monomeric Lsm1-7 complex is $81 \mathrm{kDa}$. Expected and observed molar masses are shown in Table 1. The light scattering (blue) and molar mass (red) are displayed. (D) Stoichiometry analysis of Lsm1-7 or PatMC/Lsm1-7 with 5'-FAM labeled U15 RNA at $0.5 \mu \mathrm{M}$, which is $>100$-fold above $K_{d}$. 

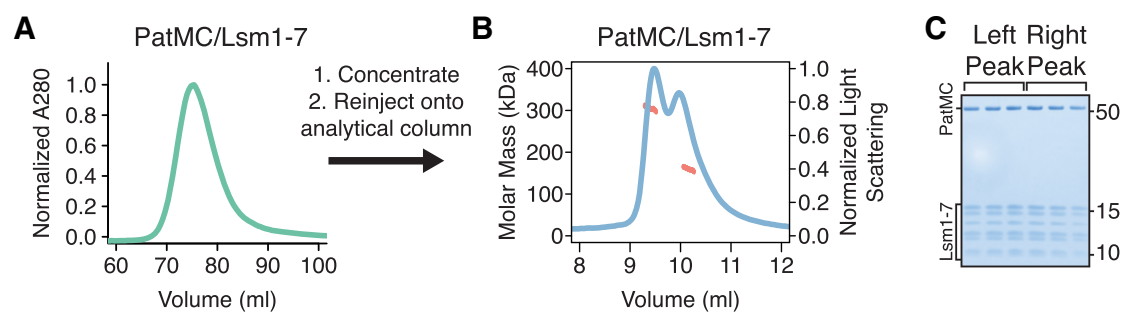

D

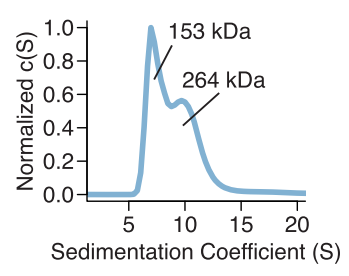

FIGURE 4. The PatMC/Lsm1-7 complex can intrinsically form a dimeric complex. (A) Preparative size exclusion chromatography of the PatMC/Lsm1-7 complex in a $400 \mathrm{mM}$ $\mathrm{NaCl}$ buffer. (B) SEC-MALS of the concentrated PatMC/Lsm1-7 complex at $250 \mathrm{mM} \mathrm{NaCl}$. The expected mass of the monomeric PatMC/Lsm1-7 complex is $133 \mathrm{kDa}$. Expected and observed molar masses are shown in Table 1. The light scattering (blue) and molar mass (red) are displayed. (C) Representative SDS-PAGE gel of peaks (left to right: earlier to later elution volumes). (D) SV-AUC of $9.3 \mu \mathrm{M}$ PatMC/Lsm1-7 at $250 \mathrm{mM} \mathrm{NaCl}$. c(S) is the sedimentation distribution with molecular weights determined from fits.

with its obligate cofactor Dcp1 (Dcp1/Dcp2 1-504, termed Dcp1/Dcp2 Ext) (Fig. 5A). Though neither PatMC nor Dcp1/ Dcp2 $2_{\text {Ext }}$ formed condensates individually, mixing stoichiometric amounts of Dcp1/Dcp2 Ext with MBP-PatMC resulted in formation of phase separated droplets (Fig. 5B; Supplemental Fig. S5A).

To understand the requirements of PatMC and Dcp1/Dcp2 Ext for droplet formation, we queried how individual regions of both complexes contribute to phase separation. The carboxy-terminal domain of Pat1 is monomeric and binds HLMs, but did not promote phase separation of Dcp1/Dcp2 Ext (Fig. 5B). Additionally, PatMC did not phase separate with a Dcp1/ Dcp2 complex containing a single HLM (Dcp2 residues 1-266, termed Dcp2 HLM1 $_{1}$ ) (Fig. 5B). These data suggest that the middle and carboxy-terminal domains of Pat1 promote phase separation of Dcp1/Dcp2 by driving self-association and binding HLMs on Dcp2, respectively. We conclude PatMC oligomerization promotes phase separation with multivalent cofactors such as Dcp2.

PatMC and Dcp2 both weakly interact with RNA, which can trigger or po-
A

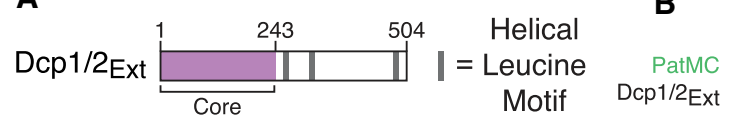

C indicating that PatMC can bridge both $5^{\prime}$ (Dcp1/Dcp2) and $3^{\prime}$ (Lsm1-7) decay factors in the context of the phase separated droplet (Fig. 5D; Supplemental Fig. S5D; ; tentiate liquid-liquid phase separation with oligomeric RNA binding proteins (RBPs) (Lin et al. 2015; Mugler etal. 2016). The PatMC/Dcp1/Dcp2 Ext droplets were able to incorporate A15 RNA, though A15 RNA did not change the critical concentration required for phase separation (Fig. 5C; Supplemental Fig. S5B). However, neither short A15 RNAs nor poly(A) RNA promoted droplet formation with either PatMC (Fig. 5C). RNA could not trigger phase separation with either Dcp1/Dcp2 Ext or PatMC alone, suggesting that the protein-protein interactions are the primary driver of phase separation between PatMC and Dcp2.

We next asked if other mRNA decay factors could be incorporated in PatMC/Dcp1/Dcp2 droplets. Lsm1-7, but not a nonspecific protein such as the unrelated Spycatcher protein, was recruited into preformed PatMC/Dcp1/Dcp2 Ext condensates,

(n)


Zakeri et al. 2012). Lsm1-7 neither phase separates with PatMC nor affects the critical concentration for droplet formation, consistent with the weak propensity of Lsm1-7 to oligomerize on its own (Supplemental Fig. S5B,C). Furthermore, Dcp1/Dcp2 Ext/PatMC/Lsm1-7 condensates recruited RNA (Supplemental Fig. S5E). These observations suggest that Pat 1 may bridge both $5^{\prime}$ and $3^{\prime}$ activities in the context of a phase separated droplet.

\section{DISCUSSION}

Our biochemical reconstitution uncovers how Pat1 broadens the specificity of the Lsm1-7 complex and promotes higher order assembly of multiple mRNA decay factors. First, Pat1 expands the Lsm1-7 complex's sequence preference by enhancing binding to adenine-rich RNAs. Second, PatMC promotes cooperative binding of Lsm1-7 to RNA, which drives oligomerization on nucleic acid. Third, the PatMC/Lsm1-7 complex has the inherent ability to oligomerize, which is dependent on Pat1 and consistent with coimmunoprecipitation data in fission yeast (Wang et al. 2017). Finally, we show that an oligomeric PatMC drives phase separation with multivalent Dcp1/Dcp2 complexes that can recruit RNA and additional decay factors to droplets. Taken together, this biochemically reconstituted system reveals that Pat1 increases the range of RNA targets bound by the Lsm1-7 complex and facilitates higher order assembly of multiple decapping factors (Fig. 6A,B).

The Lsm1-7 ring is the high affinity RNA binding component of the Pat1/Lsm1-7 complex and has a preference for U-rich oligonucleotides (Chowdhury et al. 2007; Wu et al. 2014; Lobel et al. 2019). Pat1 broadens the specificity of the Lsm1-7 complex by enhancing the affinity of Lsm1-7 for oligonucleotides with higher adenine content (Fig. 1; Chowdhury et al. 2013; Lobel et al. 2019). Because PatMC does not bind RNA with appreciable affinity on its own, we suggest that Pat1 may allow the Lsm1-7 complex to bind sequences which it has inherently weaker affinity for and therefore expand the complex's target repertoire (Supplemental Fig. S1G; Lobel et al. 2019).

Though PatMC increases the range of RNA substrates bound by Lsm1-7, it is unclear if all RNA targets bind in
A

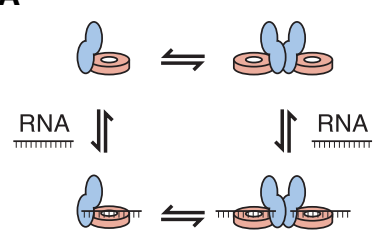

B

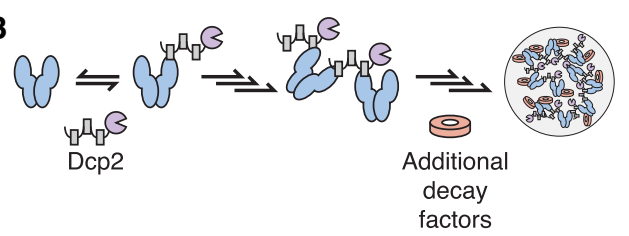

FIGURE 6. Model for how Pat1 increases specificity and assembly for different mRNA decay factors. (A) Proposed thermodynamic coupling between Pat1 (blue), Lsm1-7 (red), and RNA binding to promote multimerization of the Pat1/Lsm1-7 complex. (B) Binding of oligomeric Pat1 assemblies to multivalent Dcp1/Dcp2 (purple) complexes promotes phase separation and recruitment of additional mRNA decay factors. the same manner. For example, PatMC does not enhance the affinity of Lsm1-7 for U15 RNA, in contrast to A15 RNA or A/U rich RNA. Moreover, higher adenine contents favor more cooperative binding of PatMC/Lsm1-7. On the other hand, Pat1/Lsm1-7 stoichiometrically binds all RNA targets as a stable dimer. While we observe tetramers with 15 mer RNAs, these assemblies are less stable than the dimeric species (Fig. 2; Supplemental Fig. S2). As this work was in review, a crystal structure of $S$. pombe Lsm1-7 with $\mathrm{U}_{5} \mathrm{~A}_{1}$ RNA was reported, demonstrating binding to the distal face of the ring, similar to the Lsm2-8 complex (Montemayor et al. 2020). Determining the binding modes of different RNAs with the Pat1/Lsm1-7 complex remains a challenge for future structural studies.

PatMC also consistently increased the cooperativity of Lsm1-7 binding to all oligonucleotides tested, suggesting a coupling between protein-protein interactions and RNA binding. In support, addition of RNAs drive formation of stable dimeric PatMC/Lsm1-7 assemblies whereas in the absence of RNA, PatMC/Lsm1-7 exists in a monomer/ dimer equilibrium. This suggests two possible pathways which the PatMC/Lsm1-7 complex can load onto RNA. First, RNA may bind to dimeric PatMC/Lsm1-7 from a preexisting monomer/dimer equilibrium. Alternatively, RNA could bind monomeric PatMC/Lsm1-7 which then forms a dimer (Fig. 6A). These pathways, could in fact, be part of a thermodynamic cycle, which is in qualitative agreement with our observations. While our analysis examined 15 mer RNAs, it would be of interest to see how longer RNAs control PatMC/Lsm1-7 assembly size and how this is regulated during RNA decay.

The inherent ability of PatMC to oligomerize drives phase separation with multivalent cofactors, such as Dcp2 containing multiple HLMs. This derives from multivalent interactions between Dcp2 and oligomeric PatMC. These droplets can recruit Lsm1-7, providing evidence that Pat1 can bring both $5^{\prime}$ and $3^{\prime}$ mRNA decay factors in close proximity in the context of these phase separated droplets (Fig. 5). Additional partners of Pat1, such as Dhh1, may cooperate to further promote droplet formation (Sachdev et al. 2019). Nucleating high local concentration of multiple decapping RBPs in the context of a phase separated droplet may be leveraged for $5^{\prime}$ and $3^{\prime}$ end communication during decay (Fig. 6B). Future work is required to understand how an oligomeric Pat1 is regulated and functions in assembling an active decapping mRNP during 5'-3' mRNA decay.

The discovery that Pat1 has the ability to oligomerize is reminiscent of the homo-hexameric bacterial Lsm-family protein, $\mathrm{Hfq}$, and its cofactor $\mathrm{Crc}$ in Pseudomonad bacteria. Recent work has demonstrated that two copies of 
Crc can bridge two $\mathrm{Hfq}$ hexamers in an RNA-dependent manner (Sonnleitner et al. 2018; Pei et al. 2019). While the details of higher order Lsm assemblies between bacteria and eukaryotes differ, oligomerization may be a conserved feature of Lsm complexes and their cofactors.

\section{MATERIALS AND METHODS}

\section{Protein expression and purification}

All proteins were expressed in BL21(DE3)* (Thermofisher) cells in LB media. Cells were grown to $O D_{600}=0.6$ at $37^{\circ} \mathrm{C}$, after which IPTG was added to $1 \mathrm{mM}$. Cells were then grown overnight at $18^{\circ} \mathrm{C}$ for $16 \mathrm{~h}$. For expression of copurified PatMC/Lsm1-7, a polycistron containing all seven Lsm proteins was cloned into site one of a pET-Duet vector, with an amino-terminal hexahistidine tag followed by a TEV cleavage sequence on Lsm1. A codon optimized PatMC (residues 296-754) was ordered from IDT and cloned into site two of the pET-Duet vector. Cells were harvested by centrifugation and lysed in appropriate buffer. For Lsm1-7 and PatMC/Lsm1-7 complexes, cells were lysed in Buffer A ( $2 \mathrm{M} \mathrm{NaCl}$, $20 \mathrm{mM}$ HEPES pH 7.5, 20 mM Imidazole, $5 \mathrm{mM} \beta \mathrm{ME}$, protease inhibitor [Roche]) by sonication. Lysate was subsequently clarified by centrifugation and the supernatant was bound to Ni-NTA resin (GE) at $4^{\circ} \mathrm{C}$ for $1 \mathrm{~h}$. The resin was then transferred to a gravity column and washed with 20 column volumes of Buffer $\mathrm{A}$ before being eluted in $25 \mathrm{~mL}$ of Buffer $\mathrm{E}(250 \mathrm{mM} \mathrm{NaCl}, 250 \mathrm{mM}$ Imidazole, $20 \mathrm{mM}$ HEPES pH 7.0, $10 \mathrm{mM} \beta \mathrm{ME}$ ). The elution was then loaded directly onto a $5 \mathrm{~mL}$ HiTrap Heparin column (GE). The heparin column was run at $2 \mathrm{~mL} / \mathrm{min}$ from a $0.25-1 \mathrm{M} \mathrm{NaCl}$ gradient over 20 column volumes. Fractions containing the appropriate protein complex were concentrated in $30 \mathrm{kD}$ concentrators (Amicon) to $\sim 2 \mathrm{~mL}$ before adding TEV overnight at $4^{\circ} \mathrm{C}$. The following day, the sample was filtered and further purified by gel filtration using a Superdex 200 16/60 column (GE). Coexpressed PatMC/Lsm1-7 was purified in $400 \mathrm{mM} \mathrm{NaCl}, 20 \mathrm{mM}$ HEPES 7.0, $1 \mathrm{mM}$ DTT and Lsm1-7 alone was purified in $150 \mathrm{mM} \mathrm{NaCl}, 20 \mathrm{mM}$ HEPES pH 7.0, $1 \mathrm{mM}$ DTT. Fractions containing protein were concentrated before being flash frozen and stored at $-80^{\circ} \mathrm{C}$.

All MBP-Pat1 fusions were purified as described previously (Lobel et al. 2019). For Spycatcher purification, a carboxy-terminal KCK tag was added (SpycatcherKCK) and purified similar to the MBP-Pat1 fusions, with the heparin step omitted. SpycatcherKCK was purified on Superdex $7516 / 60$ column in $150 \mathrm{mM} \mathrm{NaCl}, 20$ $\mathrm{mM}$ HEPES $\mathrm{pH}$ 7.0, $0.5 \mathrm{mM}$ TCEP.

\section{Fluorescence polarization}

All fluorescent polarization experiments were performed in 200 $\mathrm{mM} \mathrm{NaCl}, 20 \mathrm{mM}$ HEPES $\mathrm{pH}$ 7.0, $1 \mathrm{mM}$ DTT, $5 \mathrm{mM} \mathrm{MgCl}_{2}$ with $0.3 \mu \mathrm{g} / \mu \mathrm{L}$ acetylated BSA (Promega). All RNAs used were labeled with $5^{\prime}$ FAM (IDT) and were used at final concentration of $500 \mathrm{pM}$. The binding experiments were conducted at $22^{\circ} \mathrm{C}$. All binding curves were fit to the following Hill model for single site binding:

$$
Y(m p)=(\max (m p)-\min (m p)) * \frac{\text { [protein }^{n}}{{\text { protein }]^{n}+K_{d}{ }^{n}}^{n}}+\min (m p) .
$$

To determine the $\Delta \mathrm{G}$ of binding, each independent replicate was fitted to the above model and $\Delta G$ was determined by the relation- ship $\Delta G=+R T^{*} \ln \left(K_{d}\right)$. The $\Delta G$ from each individual fit was averaged and plotted with standard deviation. Hill coefficients were averaged from fitting three separate binding isotherms and shown with standard deviation.

For analysis of stoichiometry, 5'-FAM RNA was kept at $0.5 \mu \mathrm{M}$ in the same buffer as used for the fluorescence polarization assay. Protein was titrated into solution containing labeled RNA and fluorescence polarization was measured for each concentration. The linear portion was fit to a linear model and the average of the last four points was used to fit a line at the saturation point. The intersection of these two lines was used to determine the binding stoichiometry.

\section{Analytical size exclusion chromatography (SEC) and SEC-MALS}

Analytical SEC was performed in buffer M $(250 \mathrm{mM} \mathrm{NaCl}, 20 \mathrm{mM}$ HEPES pH 7.0, $1 \mathrm{mM}$ DTT), or in the appropriate $\mathrm{NaCl}$ concentration. Samples were mixed at $\sim 30 \mu \mathrm{M}$ and incubated for $15 \mathrm{~min}$ in $350 \mathrm{mM} \mathrm{NaCl}, 20 \mathrm{mM}$ HEPES pH 7.0, 1 mM DTT on ice before being filtered and injected onto a GE Superdex 200 10/300-Increase analytical size exclusion column. When appropriate, samples were mixed with 1.1-fold molar excess RNA. All samples were run at $0.35 \mathrm{~mL} / \mathrm{min}$, and peaks were analyzed by SDS-PAGE (Invitrogen). For experiments involving reinjection of fractions over SEC, $500 \mu \mathrm{L}$ of fractions were spin filtered before reinjecting over SEC.

For SEC-MALS, $165 \mu \mathrm{g}$ of sample was filtered through a $0.1 \mu \mathrm{m}$ spin filter (Amicon) before being injected onto a preequilibrated KW-804 column (Shodex). For samples with RNA, stoichiometric amounts of RNA were added prior to spin filtration. Data was acquired with an inline DAWN HELEOS MALS and Optilab rEX differential refractive index detector (Wyatt Technology). All analysis was performed using ASTRA VI software (Wyatt Technology). Data was then exported and plotted with $\mathrm{R}$.

\section{Analytical ultracentrifugation}

Sample was buffer exchanged into buffer M using Zeba spin columns (Thermofisher) and diluted to $9.3 \mu \mathrm{M}$. When appropriate, stoichiometric amounts of RNA were added to the sample after buffer exchange. AUC cells were assembled according to manufacturer's protocol and $100 \mu \mathrm{L}$ of sample was loaded into the cell. The sample was incubated at $22^{\circ} \mathrm{C}$ for $>2 \mathrm{~h}$ prior to centrifugation. Samples were run at 30,000 rpm for 10-12 h in a Beckman XL/A analytical ultracentrifuge. Scans for samples containing only protein were collected at $280 \mathrm{~nm}$, and samples containing RNA were scanned at both 280 and $260 \mathrm{~nm}$. Sedimentation velocity analysis was performed in SEDFIT (NIH) and plots were generated with GUSSI (Schuck 2003; Brautigam 2015). Experimental parameters were determined using SEDNTERP $(\mathrm{NIH})$. The following parameters were used for fitting: partial volume, 0.739818 ; buffer density, 1.0101; buffer viscosity, 0.0104032 .

\section{Protein labeling}

For labeling with dyes, proteins were buffer exchanged into appropriate labeling buffer using Zeba spin columns (Thermofisher). Lsm1-7 and SpycatcherKCK were labeled with 
fivefold molar excess Alexa Fluor 555 maleimide for $1 \mathrm{~h}$ at room temperature in $150 \mathrm{mM} \mathrm{NaCl}, 20 \mathrm{mM}$ HEPES pH 7.5, $0.5 \mathrm{mM}$ TCEP. Reactions were quenched by addition of $\beta M E$ to a final concentration of $10 \mathrm{mM}$. MBP-PatMC was labeled with fourfold molar excess NHS-Fluorescein (Thermofisher) for $1 \mathrm{~h}$ at room temperature in $150 \mathrm{mM} \mathrm{NaCl}, 150 \mathrm{mM}$ Sodium bicarbonate $\mathrm{pH} 8.4$ before being quenched by adding TRIS- $\mathrm{HCl}$ pH 8.0 to a final concentration of $50 \mathrm{mM}$. All quenching steps were performed at room temperature for $20 \mathrm{~min}$. Free dye was separated from labeled protein by Illustra NICK columns (GE) according to the manufacturer's instruction. Labeling efficiency and concentrations were calculated by UV-vis spectroscopy.

\section{Microscopy}

All images were acquired with Nikon Eclipse Ti equipped with a $40 \times$ dry lens. Samples were prepared in a 384 well plate (Greiner) that was cleaned with $0.1 \mathrm{M} \mathrm{NaOH}$ and passivated with PEG-silane and $100 \mathrm{mg} / \mathrm{mL}$ BSA (Sigma-Aldrich) before being washed with water to remove residual BSA. Proteins or RNA were mixed at specified concentrations in a final buffer concentration of $60 \mathrm{mM} \mathrm{NaCl}, 20 \mathrm{mM}$ HEPES pH 7.0, 1 mM DTT. When appropriate, dye-labeled protein or RNA were added to $100 \mathrm{nM}$. Samples were incubated at room temperature for 20 min prior to imaging. Images were analyzed in FIJI (Schindelin et al. 2012).

\section{SUPPLEMENTAL MATERIAL}

Supplemental material is available for this article.

\section{ACKNOWLEDGMENTS}

We thank Alexandra Rizo and Serena Sanulli for experimental guidance; the Nikon Imaging Center at UCSF for use of the microscope; Daniel Southworth's lab for use of SEC-MALS; Ryan Tibble, Nathan Gamarra, Eva Absmeier, and Lori Passmore for comments on the manuscript. This work was supported by U.S. National Institutes of Health grant R01GM078360 to J.D.G.

Received April 9, 2020; accepted May 29, 2020.

\section{REFERENCES}

Banani SF, Lee HO, Hyman AA, Rosen MK. 2017. Biomolecular condensates: organizers of cellular biochemistry. Nat Rev Mol Cell Biol 18: 285-298. doi:10.1038/nrm.2017.7

Bonnerot C, Boeck R, Lapeyre B. 2000. The two proteins Pat1p (Mrt1p) and Spb8p interact in vivo, are required for mRNA decay, and are functionally linked to Pab1 p. Mol Cell Biol 20: 5939-5946. doi:10.1128/MCB.20.16.5939-5946.2000

Bouveret E, Rigaut G, Shevchenko A, Wilm M, Séraphin B. 2000. A Sm-like protein complex that participates in mRNA degradation. EMBO J 19: 1661-1671. doi:10.1093/emboj/19.7.1661

Brautigam CA. 2015. Calculations and publication-quality illustrations for analytical ultracentrifugation data. Methods Enzymol 562: 109-133. doi:10.1016/bs.mie.2015.05.001

Chang H, Lim J, Ha M, Kim VN. 2014. TAIL-seq: genome-wide determination of poly(A) tail length and $3^{\prime}$ end modifications. Mol Cell 53: 1044-1052. doi:10.1016/j.molcel.2014.02.007
Charenton C, Gaudon-Plesse C, Fourati Z, Taverniti V, Back R, Kolesnikova O, Séraphin B, Graille M. 2017. A unique surface on Pat1 C-terminal domain directly interacts with Dcp2 decapping enzyme and Xrn1 5'-3' mRNA exonuclease in yeast. Proc Natl Acad Sci 114: E9493-E9501. doi:10.1073/pnas.1711680114

Chowdhury A, Mukhopadhyay J, Tharun S. 2007. The decapping activator Lsm1p-7p-Pat1p complex has the intrinsic ability to distinguish between oligoadenylated and polyadenylated RNAs. RNA 13: 998-1016. doi:10.1261/rna.502507

Chowdhury A, Kalurupalle S, Tharun S. 2013. Pat1 contributes to the RNA binding activity of the Lsm1-7-Pat1 complex. RNA 20: 14651475. doi:10.1261/rna.045252.114

Fromm SA, Kamenz J, Noldeke ER, Neu A, Zocher G, Sprangers R. 2014. In vitro reconstitution of a cellular phase-transition process that involves the mRNA decapping machinery. Angew Chem Int Ed Engl 53: 7354-7359. doi:10.1002/anie.201402885

He F, Celik A, Wu C, Jacobson A. 2018. General decapping activators target different subsets of inefficiently translated mRNAs. Elife 7: e34409. doi:10.7554/eLife.34409

Hubstenberger A, Courel M, Bénard M, Souquere S, Ernoult-Lange M, Chouaib R, Yi Z, Morlot JB, Munier A, Fradet M, et al. 2017. P-body purification reveals the condensation of repressed mRNA regulons. Mol Cell 68: 144-157.e5. doi:10.1016/j.molcel.2017.09.003

Jonas S, Izaurralde E. 2015. Towards a molecular understanding of microRNA-mediated gene silencing. Nat Rev Genet 16: 421433. doi:10.1038/nrg3965

Kurosaki T, Popp MW, Maquat LE. 2019. Quality and quantity control of gene expression by nonsense-mediated mRNA decay. Nat Rev Mol Cell Biol 20: 406-420. doi:10.1038/s41580-0190126-2

Lim J, Ha M, Chang H, Kwon SC, Simanshu DK, Patel DJ, Kim VN. 2014. Uridylation by TUT4 and TUT7 marks mRNA for degradation. Cell 159: 1365-1376. doi:10.1016/j.cell.2014.10.055

Lin Y, Protter DSW, Rosen MK, Parker R. 2015. Formation and maturation of phase-separated liquid droplets by RNA-binding proteins. Mol Cell 60: 208-219. doi:10.1016/j.molcel.2015.08.018

Lobel JH, Tibble RW, Gross JD. 2019. Pat1 activates late steps in mRNA decay by multiple mechanisms. Proc Natl Acad Sci 116: 23512-23517. doi:10.1073/pnas. 1905455116

Mitchell SF, Jain S, She M, Parker R. 2012. Global analysis of yeast mRNPs. Nat Struct Mol Biol 20: 127-133. doi:10.1038/nsmb.2468

Montemayor EJ, Virta JM, Hayes SM, Nomura Y, Brow DA, Butcher SE. 2020. Molecular basis for the distinct cellular functions of the Lsm1-7 and Lsm2-8 complexes. bioRxiv doi:10.1101/2020.04 .22 .055376

Moore MJ. 2005. From birth to death: the complex lives of eukaryotic mRNAs. Science 309: 1514-1518. doi:10.1126/science.1111443

Mugler CF, Hondele M, Heinrich S, Sachdev R, Vallotton P, Koek AY, Chan LY, Weis K. 2016. ATPase activity of the DEAD-box protein Dhh1 controls processing body formation. Elife 5: e18746. doi:10.7554/eLife.18746

Mugridge JS, Coller J, Gross JD. 2018. Structural and molecular mechanisms for the control of eukaryotic $5^{\prime}-3^{\prime}$ mRNA decay. Nat Struct Mol Biol 25: 1077-1085. doi:10.1038/s41594-018-0164-z

Mullen TE, Marzluff WF. 2008. Degradation of histone mRNA requires oligouridylation followed by decapping and simultaneous degradation of the mRNA both $5^{\prime}$ to $3^{\prime}$ and $3^{\prime}$ to $5^{\prime}$. Genes Dev 22: 50-65. doi:10.1101/gad.1622708

Nissan T, Rajyaguru P, She M, Song H, Parker R. 2010. Decapping activators in Saccharomyces cerevisiae act by multiple mechanisms. Mol Cell 39: 773-783. doi:10.1016/j.molcel.2010.08.025

Pei XY, Dendooven T, Sonnleitner E, Chen S, Luisi BF. 2019. Architectural principles for $\mathrm{Hfq} / \mathrm{Crc}$-mediated regulation of gene expression. Elife 8: e43158. doi:10.7554/eLife.43158 
Pilkington GR, Parker R. 2008. Pat1 contains distinct functional domains that promote $P$-body assembly and activation of decapping. Mol Cell Biol 28: 1298-1312. doi:10.1128/MCB.00936-07

Rissland OS, Norbury CJ. 2009. Decapping is preceded by $3^{\prime}$ uridylation in a novel pathway of bulk mRNA turnover. Nat Struct Mol Biol 16: 616-623. doi:10.1038/nsmb.1601

Sachdev R, Hondele M, Linsenmeier M, Vallotton P, Mugler CF, Arosio P, Weis K, Zurich ETH. 2019. Pat1 promotes processing body assembly by enhancing the phase separation of the DEADbox ATPase Dhh1 and RNA. Elife 8: e41415. doi:10.7554/eLife .41415

Schindelin J, Arganda-Carreras I, Frise E, Kaynig V, Longair M, Pietzsch T, Preibisch S, Rueden C, Saalfeld S, Schmid B, et al. 2012. Fiji: an open-source platform for biological-image analysis. Nat Methods 9: 676-682. doi:10.1038/nmeth.2019

Schuck P. 2003. On the analysis of protein self-association by sedimentation velocity analytical ultracentrifugation. Anal Biochem 320: 104-124. doi:10.1016/S0003-2697(03)00289-6

Schutz S, Noldeke ER, Sprangers R. 2017. A synergistic network of interactions promotes the formation of in vitro processing bodies and protects mRNA against decapping. Nucleic Acids Res 45: 6911-6922. doi:10.1093/nar/gkx353

Sharif H, Ozgur S, Sharma K, Basquin C, Urlaub H, Conti E. 2013. Structural analysis of the yeast Dhh1-Pat1 complex reveals how Dhh1 engages Pat1, Edc3 and RNA in mutually exclusive interactions. Nucleic Acids Res 41: 8377-8390. doi:10.1093/nar/gkt600

Sheth U, Parker R. 2003. Decapping and decay of messenger RNA occur in cytoplasmic processing bodies. Science 300: 805-808. doi:10.1126/science.1082320

Sonnleitner E, Wulf A, Pei X, Wolfinger T, Forlani G, Prindl K, Abdou L, Resch A, Allain H, Luisi BF, et al. 2018. Interplay between the catabolite repression control protein $\mathrm{Crc}, \mathrm{Hfq}$ and RNA in Hfq-dependent translational regulation in Pseudomonas aeruginosa. Nucleic Acids Res 46: 1470-1485. doi:10.1093/nar/gkx1245

Teixeira D, Parker R. 2007. Analysis of P-body assembly in Saccharomyces cerevisiae. Mol Biol Cell 18: 2274-2287. doi:10 .1091/mbc.e07-03-0199
Tharun S, Parker R. 2001. Targeting an mRNA for decapping: displacement of translation factors and association of the Lsm 1p-7p complex on deadenylated yeast mRNAs. Mol Cell 8: 1075-1083. doi:10.1016/S1097-2765(01)00395-1

Tharun S, He W, Mayes AE, Lennertz P, Beggs JD, Parker R. 2000. Yeast $\mathrm{Sm}$-like proteins function in mRNA decapping and decay. Nature 404: 515-518. doi:10.1038/35006676

Vindry C, Marnef A, Broomhead H, Twyffels L, Ozgur S, Stoecklin G, Llorian M, Smith CW, Mata J, Weil D, et al. 2017. Dual RNA processing roles of Pat1b via cytoplasmic Lsm1-7 and nuclear Lsm28 complexes. Cell Rep 20: 1187-1200. doi:10.1016/j.celrep .2017 .06 .091

Wang C-Y, Wang Y-T, Hsiao W-Y, Wang S-W. 2017. Involvement of fission yeast Pdc2 in RNA degradation and P-body function. RNA 23: 493-503. doi:10.1261/rna.059766.116

Webster MW, Chen Y, Stowell JAW, Alhusaini N, Sweet T, Graveley BR, Coller J, Passmore LA. 2018. mRNA deadenylation is coupled to translation rates by the differential activities of Ccr4-not nucleases. Mol Cell 70: 1089-1100. doi:10.1016/j .molcel.2018.05.033

Wu D, Muhlrad D, Bowler MW, Jiang S, Liu Z, Parker R, Song H. 2014. Lsm2 and Lsm3 bridge the interaction of the Lsm1-7 complex with Pat1 for decapping activation. Cell Res 24: 233-246. doi:10.1038/ cr.2013.152

Wyatt PJ. 1993. Light scattering and the absolute characterization of macromolecules. Anal Chim Acta 272: 1-40. doi:10.1016/00032670(93)80373-S

Xing W, Muhlrad D, Parker R, Rosen MK. 2018. A quantitative inventory of yeast $P$ body proteins reveals principles of compositional specificity. bioRxiv. doi:10.1101/489658

Yi H, Park J, Ha M, Lim J, Chang H, Kim VN. 2018. PABP cooperates with the CCR4-NOT complex to promote mRNA deadenylation and block precocious decay. Mol Cell 70: 1081-1088. doi:10 .1016/j.molcel.2018.05.009

Zakeri B, Fierer JO, Celik E, Chittock EC, Schwarz-linek U, Moy VT, Howarth M. 2012. Peptide tag forming a rapid covalent bond to a protein, through engineering a bacterial adhesin. Proc Natl Acad Sci 109: E690-E697. doi:10.1073/pnas.1115485109 

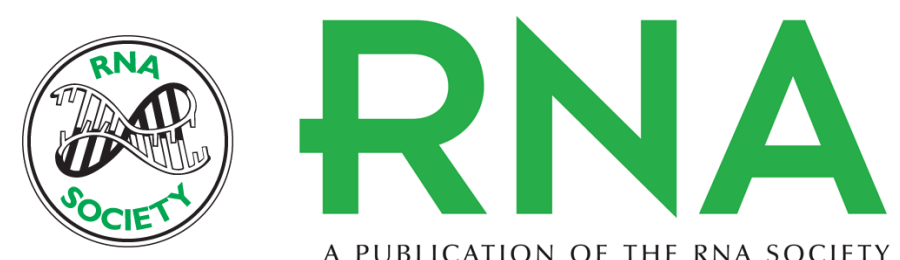

A PUBLICATION OF THE RNA SOCIETY

\section{Pdc2/Pat1 increases the range of decay factors and RNA bound by the Lsm1 -7 complex}

Joseph H. Lobel and John D. Gross

RNA 2020 26: 1380-1388 originally published online June 8, 2020

Access the most recent version at doi:10.1261/rna.075812.120

\section{Supplemental http://rnajournal.cshlp.org/content/suppl/2020/06/08/rna.075812.120.DC1 Material}

References This article cites 43 articles, 13 of which can be accessed free at: http://rnajournal.cshlp.org/content/26/10/1380.full.html\#ref-list-1

Open Access Freely available online through the RNA Open Access option.

Creative This article, published in RNA, is available undera Creative Commons License Commons (Attribution 4.0 International), as described at

License http://creativecommons.org/licenses/by/4.0/.

Email Alerting Receive free email alerts when new articles cite this article - sign up in the box at the Service top right corner of the article or click here.

\section{|||||||| Providing Precise Solutions for your research.}

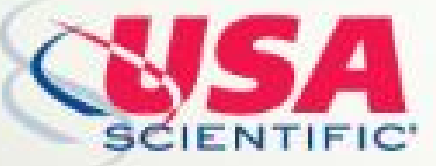

To subscribe to $R N A$ go to:

http://rnajournal.cshlp.org/subscriptions

(C) 2020 Lobel and Gross; Published by Cold Spring Harbor Laboratory Press for the RNA Society 